\title{
Evolving heat waves characteristics challenge heat warning systems and prevention plans
}

\author{
Mathilde Pascal $^{1} \cdot$ Robin Lagarrigue $^{1} \cdot$ Anouk Tabai $^{1} \cdot$ Isabelle Bonmarin $^{1} \cdot$ Sacha Camail $^{1} \cdot$ Karine Laaidi $^{1}$. \\ Alain Le Tertre ${ }^{1} \cdot$ Sébastien Denys ${ }^{1}$
}

Received: 11 August 2020 / Revised: 8 February 2021 / Accepted: 28 March 2021 / Published online: 3 April 2021

(C) ISB 2021

\begin{abstract}
This paper analyses how recent trends in heat waves impact heat warning systems. We performed a retrospective analysis of the challenges faced by the French heat prevention plan since 2004. We described trends based on the environmental and health data collected each summer by the French heat warning system and prevention plan. Major evolutions of the system were tracked based on the evaluations organized each autumn with the stakeholders of the prevention plan. Excess deaths numbering 8000 were observed during heat waves between 2004 and 2019, 71\% of these between 2015 and 2019. We observed major changes in the characteristics, frequency and the geographical spread of heat waves since 2015. Feedbacks led to several updates of the warning system such as the extension of the surveillance period. They also revealed that risk perception remained limited among the population and the stakeholders. The sharp increase in the number of heat warnings issued per year since 2015 challenges the acceptability of the heat warnings. Recent heat waves without historical equivalent interfere with the development of evidencebased prevention strategies. The growing public health impacts heat waves emphasize the urgent need to act to adapt the population, at different levels of intervention, from individual comportments to structural modifications. A specific attention should be given to increase the resources allocated to the evaluation and the management of heat-related risks, especially considering the needs to catch with the rapid rhythm of the changing climate.
\end{abstract}

Keywords Climate change $\cdot$ Heat wave $\cdot$ Heat warning system $\cdot$ Heat prevention plan

\section{Introduction}

Exposure to heat results in multiple physiological stresses (cardiovascular, renal, respiratory...), leading to an increase in mortality and morbidity (e.g. emergency room visits, general practitioner's consultations, for multiple health outcomes) (Hanna and Tait 2015). Epidemiological studies in the Northern hemisphere have consistently documented the relationship between exposure to heat and mortality (Basu 2009; Anderson and Bell 2009; Gasparrini et al. 2015; Green et al. 2019; Pascal et al. 2018). This relationship depends on the background temperature distribution, which may indicate an acclimatization of the population to its climate (Gasparrini et al. 2015; Pascal et al. 2018; Hajat and Kosatky 2010). It is

Mathilde Pascal

Mathilde.Pascal@ santepubliquefrance.fr

1 Santé publique France, 12 Rue du Val d'Osne, 94415 Saint Maurice, France also influenced by environmental and sociodemographic determinants (Benmarhnia et al. 2015), and by the spread of air conditioning (Ito et al. 2018; Sera et al. 2020).

The mortality response to heat is highly non-linear, and a small increase in temperature may have dramatic health consequences. For instance, in France, between 2000 and 2010, a mean temperature of $26^{\circ} \mathrm{C}$ was associated with a relative risk cumulated over 21 days of 1.035 [1.000;1.071], and a mean temperature of $28^{\circ} \mathrm{C}$ with a relative risk of 1.432 [1.293:1.586] (Pascal et al. 2018). Due to this non-linearity and to the rapidity of the health impacts (mostly observed 24 $\mathrm{h}-72 \mathrm{~h}$ after exposure), extreme temperatures have the potential to disrupt the health care system, especially when they are persistent over time, leading to so-called "heat waves". 70,000 excess deaths were recorded during the 2003 heat wave in Europe (Robine et al. 2008), including 14,800 victims between the $1^{\text {st }}$ and the $15^{\text {th }}$ August in France (Le Tertre et al. 2006). In 2010, 11,000 excess deaths were observed during a two-week heat wave in Moscow (Shaposhnikov et al. 2014). Heat waves generally correspond to the exceedance of pre- 
defined temperature thresholds during several days, with great variations in the definitions and a lack of international consensus on what actually is a heat wave (Tong et al. 2015; Perkins 2015; Xu et al. 2016).

Definitions developed for climatological purposes usually differ from definitions developed for epidemiological purposes (Basarin et al. 2020). Climatic trends in heat waves have been extensively described (Russo et al. 2015; Russo et al. 2014; Soubeyroux et al. 2016; Chapman et al. 2019; Sheridan and Lee 2018; Piticar 2018). It is highly probable that climate change has increased the frequency of heat waves since the 1950s in most parts of Europe (Solomon et al. 2007), and has aggravated the intensity of extreme heat worldwide (Diffenbaugh et al. 2017). For instance, record-breaking heat waves of summer 2019 in Europe would have been 1.5 to $3^{\circ} \mathrm{C}$ cooler without climate change (Vautard et al. 2019; vanOldenborgh et al. 2019). In France, the mean number of heat waves days per year and department (defined by the French weather service Météo-France as several days with a mean temperature above the $97.5^{\text {th }}$ percentile of the 19812010 temperature distribution, and at least one day above the $99.5^{\text {th }}$ percentile) has increased from 1 in the 1960 s to 5 in the 2010s (Soubeyroux et al. 2016). Eight of the 10 warmest years since 1900 were observed after 2000, 4 of them after 2015 (2015, 2017, 2018, 2019).

In Europe, proactive adaptation to heat, and especially to extreme heat, should be a public health priority. In 2019 at least 16 European countries had implemented heat prevention plans and warning systems (Basarin et al. 2020; Casanueva et al. 2019). Heat warning systems are usually based on up-todate science combining weather forecasts and epidemiological data (Lowe et al. 2011; McGregor et al. 2015). Several methods have been proposed to developed decision thresholds based on models of the response of mortality or morbidity to temperatures. However, how to select thresholds that would lead to efficient interventions, while being acceptable in terms of frequency remains an open question. Furthermore, operating a heat warning system implies more than the forecasting of a temperature exceeding a threshold. An efficient warning must lead to rapid decisions and actions, mobilizing several actors in a context of uncertainties and constraint resources. While early warning systems are classical tools in the field of meteorology and public health, heat early warning systems have challenging specificities. Meteorological warning systems generally target localized acute events (e.g. hurricanes, floods...), with a risk that is perceivable, and visible impacts on infrastructure for instance. The immediate response is centered on the protection of the exposed population, and its utility is rarely questioned. By contrast, heat waves can be geographically extended and long-lasting, and, in France, they are not perceived as dangerous by most people, including key decision-makers (Laaidi et al. 2019a). Multiple heat wave definitions and thresholds may co-exist for the same territory, making it difficult to understand what is going on (e.g. in France, the definition used by the heat warning system differs from the definition used by Météo-France for its studies of climate change). The impacts are not immediately visible, and multiple stakeholders, who may question the need for actions, are involved in the protection of the population. Finally, while early warning systems are also frequently used by public health practitioners, they are traditionally based on the observations of unusual health impacts. In the case of heat waves, health warning are based on a predicted health impacts based on environmental forecasts, and health indicators are used to support decision-making during and after the events (Campbell et al. 2018). While relying on environmental forecast is a powerful tool to avoid adverse health impacts, there may be a tendency for some decision-makers to wait for the observation of a large health impacts to justify costly interventions. Finally, an additional difficulty lies in the rapid evolution of the climate, resulting in a growing number of events without historical equivalent, which limits the possibility of predicting the possible impacts.

Current heat warning systems and plans have been reviewed and evaluated based on surveys and analyses of their publications (Casanueva et al. 2019; Bittner et al. 2014). An insight of the practical difficulties encountered by those plans is however seldom discussed. Furthermore, in the recent years, we observed an acceleration in the changing characteristics of heat waves in Europe, which is not fully taken into account in current evaluations and publications. In this paper, we illustrate how recent trends in heat waves characteristics and their associated impacts challenged the heat wave warning system and the prevention strategies of the French heat wave management plan, and discuss research need to overcome those challenges.

\section{Method}

The French heat warning system is jointly operated by the French public health agency Santé publique France, and the French weather agency Météo-France. It focuses on periods of sustain heat that are so unusual (corresponding to the $99.5^{\text {th }}$ percentile of the 1981-2010 temperature distribution) that they justify the wide broadcast of behavioral advices, and short-term changes in life style (e.g. modifying working hours, canceling outdoor sportive activities, organizing freshwater distribution in public transportation, opening public spaces during the night...).

Our analysis is based on data collected each year by the French heat warning system and prevention plans. This includes weather and health data, knowledge on risk perception, actions taken at the local level, and outcome of the feedbacks organized each year to improve the processes. Most of this data is unpublished, or published in the grey literature, for 
instance in the weekly reports produced during heat waves. The key components of the heat warning system and prevention plans are briefly described below. To underline recent challenges, we focused on heat waves observed between 2015 and 2019, underlying their specificities compared to previous events.

\section{Meteorological warnings}

Daily minimum and maximum temperatures are provided by Météo-France. While the heat warning system was implemented in 2004, a historical database of heat waves in France was built using the French heat warning system definitions, and a reconstruction of past temperatures since the 1970s (Santé publique France 2020; Pascal et al. 2019).

Heat waves correspond to periods when the minimum and maximum temperatures averaged over 3 days exceed local thresholds (the range of thresholds are described in Supplementary material Fig. S1). The choice of the thresholds has been detailed in previous papers (Pascal et al. 2013; Pascal et al. 2006), and the system was involved in an intercomparison test where it shows a good capacity to identify periods of high excess mortality (Hajat et al. 2010).

Departmental heat waves are described based on their daily severity, which is computed as the difference between the observed temperatures and the thresholds ((TmaxThresholdmax)+(Tmin-Thresholdmin)). The duration is the number of days when the minimum and maximum thresholds are exceeded simultaneously. The cumulated severity is the sum of the daily severities during the heat wave. The intensity is the maximum of the daily severities during the heat wave. National heat waves are described similarly, with a national severity computed as the population-weighted mean of the departmental severities.
In practice, the warning decision relies on the probability that the forecasted 3-day averaged temperatures exceed the thresholds. It takes into account a critical analysis of the forecast uncertainties, as well as possible aggravating factors (e.g. high humidity levels, air pollution, earliness, duration...), contextual factors (e.g. holiday weekends...) and, when available, health surveillance data. Heat warnings are graded on a four-color scale; green (no risk), yellow (moderate risk, e.g. forecasts slightly below thresholds), orange (high risk, forecasts above thresholds) and red (extreme risk, forecasts above thresholds associated with an exceptional intensity).

\section{Health surveillance}

Health indicators were selected based on data availability and quality, strength of evidence of an association with heat, and sensitivity and specificity of this association (Pascal et al. 2012) (Table 1). During heat waves, those data are analyzed daily, and a summary assessment is published weekly on the Santé publique France website. Trends in morbidity data can be interpreted with a one-day lag, but two days are needed to consolidate the data. Trends in mortality can be interpreted qualitatively after two weeks, but it takes a month to obtain consolidated data. Therefore, mortality is never used to support decision-making during a heat wave.

A description of the excess mortality observed during each summer is published by Santé publique France yearly. It is estimated by comparing the observed mortality to a reference mortality based on the 1 to 5 previous years. Although it is a simple approach, it provides an appropriate order of magnitude of the impacts (Antics et al. 2013). Results are reported as absolute numbers (to facilitate comparison with other type of extreme events) and excess mortality rate over the heat wave period. During heat waves, data at the national and regional

Table 1 Health indicators monitored for the heat wave management plan

\begin{tabular}{|c|c|c|c|}
\hline Indicator & Data source & Comments & Use \\
\hline $\begin{array}{l}\text { Emergency room visits for hyperthermia } \\
\text { (ICD-X: T67,X30), dehydration (ICD-X: } \\
\text { E86) or hyponatremia (ICD-X: E87.1), } \\
\text { all ages and by age as a primary or second } \\
\text { cause of diagnosis }\end{array}$ & $\begin{array}{l}\text { OSCOUR } ® \text { (Organisation de la } \\
\text { surveillance coordonnée des } \\
\text { urgences) (Josseran et al. 2010; } \\
\text { Caserio Schonemann et al. 2014) }\end{array}$ & $\begin{array}{l}\text { Data can be interpreted with a 1-day lag } \\
\text { Representing between } 56 \text { and } 100 \% \text { of } \\
\text { the emergency room visits depending of } \\
\text { the area, } 92 \% \text { nationally }\end{array}$ & $\begin{array}{l}\text { Near-real time } \\
\text { decision making } \\
\text { during heat } \\
\text { waves Impact } \\
\text { assessment }\end{array}$ \\
\hline $\begin{array}{l}\text { Emergency consultations by general } \\
\text { practitioners for heat stroke (ICD-X: } \\
\text { T67,X30) or dehydration (ICD-X: E86), } \\
\text { all ages and by age, as a primary or } \\
\text { second cause of diagnosis }\end{array}$ & $\begin{array}{l}\text { Associations SOS-Médecins } \\
\quad \text { (Caserio Schonemann et al. 2014) }\end{array}$ & $\begin{array}{l}\text { Data can be interpreted with a 1-day lag } \\
\text { Only for the main urban centers, } \\
\text { representing about } 7 \% \text { of total general } \\
\text { practitioners consultations in France }\end{array}$ & $\begin{array}{l}\text { Near-real time } \\
\text { decision making } \\
\text { during heat } \\
\text { waves Impact } \\
\text { assessment }\end{array}$ \\
\hline All-cause mortality, all ages and by ages & $\begin{array}{l}\text { National Institute of Statistics and } \\
\text { Economic Studies (Insee) for a } \\
\text { sample of } 3000 \text { municipalities }\end{array}$ & $\begin{array}{l}\text { Data can be interpreted after two weeks } \\
\text { (qualitative trends after two weeks, } \\
\text { numbers after one month) Representing } \\
\text { between } 67 \text { and } 89 \% \text { of mortality } \\
\text { depending of the area, } 80 \% \text { nationally }\end{array}$ & Impact assessment \\
\hline
\end{tabular}


scale are shared daily with stakeholders to support decisionmaking, and published weekly.

While the heat warning system was implemented in 2004, a reconstruction of past events and past mortality impacts since 1970 was performed using comparable method, to build a historical database of the excess mortality observed during heat waves in France (Santé publique France 2020; Pascal et al. 2019).

\section{Prevention strategies}

Each summer, leaflets and posters are largely disseminated to local stakeholders (regional health agencies, prefects, mayors, NGO's, health professionals, employers, schools, etc ...) (David 2015). They provide recommendations for the general population, for the elderly, and for workers (Fig. 1). They were edited to fit the needs of individuals with low literacy. Radio and TV spots are broadcasted through media requisition by the Ministry of Health during heat waves (David 2015). Leaflets, posters and TV or radio spots describe how to keep cool and hydrated, and what are the first symptoms of heat-related illness. A large panel of measures can also be implemented at the local and national levels, such as communication, launching of nursing homes and hospitals management plans, call centres to answer frequently ask questions and provide advices. Each city manages a registry were people feeling that they need assistance during heat waves may register. Then, they would benefit from daily calls, or sometimes visits, from a municipal social workers. Locally, sports or cultural events may be cancelled if the heat is too intense. However, all these measures are not systematically recorded, and data is available only on the dissemination of the communication tools.

\section{Evaluation: internal feedbacks and ad hoc studies}

Evaluation relies on two complementary approaches: internal feedbacks to identify operational problems and study needs, and specific studies to improve the scientific foundations of the warning system and prevention plan.

Annual feedbacks are organized to discuss the relevance of the warning decisions, the coordination between internal services and outside partners (Ministry of Health, Ministry of Labour, Weather services, etc.), the preventive actions, and the needs for evolution. Feedbacks are based on timelines of the warnings, and on surveys of the stakeholders involved in the warnings, to identify potential sources of errors, delays and need of improvements. They typically include a retrospective description of the warnings and associated impacts, with a comparison to the previous years, and an analysis of the discrepancies between forecasts and observations. Unfortunately, a comprehensive review of all the preventive actions taken at the local level is not analyzed during those feedbacks, which focus on preventive actions taken at the national level (e.g. communication).

Complementary to those feedbacks, specific studies have been developed to further support the ongoing evolution of the heat warning system and the prevention plan. Epidemiological studies analyzed the mortality and morbidity responses (Pascal et al. 2018; Atiki et al. 2018), and proposed evolution of the warning thresholds (Le Tertre et al. 2020). Several surveys investigated the knowledge, attitudes, beliefs and practices concerning heat risks and prevention among the population (Laaidi et al. 2019a; Léon et al. 2007).
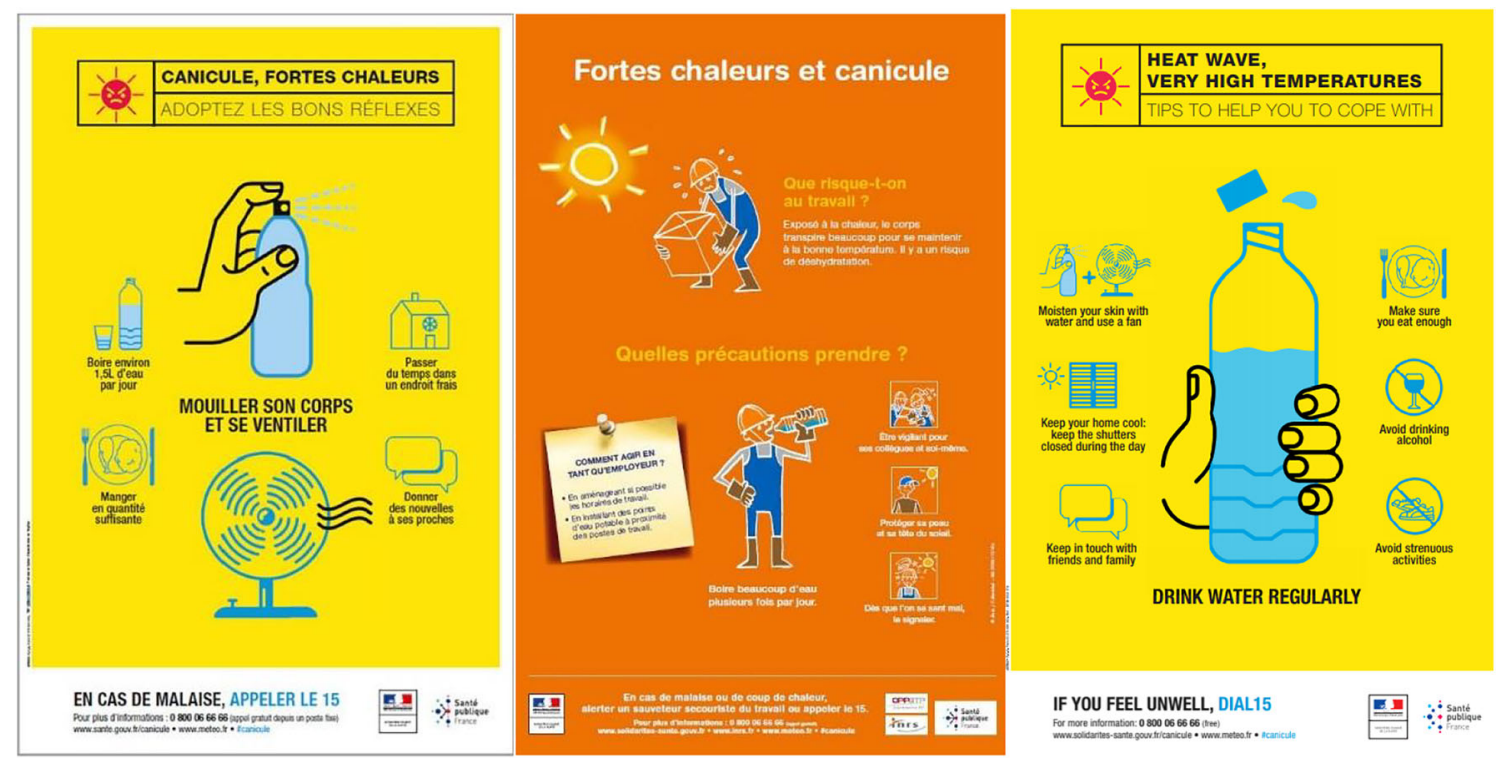

Fig. 1 Examples of prevention leaflets used in 2019 


\section{Results}

\section{Meteorological warnings facing rapidly changing trends in heat waves characteristics}

Table 2 summarizes the main trends in historical heat waves. Since the 2000s, all the metropolitan French departments experienced at least one heat wave per decade. Since 2015, all but one metropolitan department has experienced at least one heat wave, and heat waves were observed every year, a pattern without historical precedent. In the 1970s and 1980s, it was more frequent to observe years without any departmental heat waves. In addition, between 2015 and 2019, 11 departments experienced at least one heat wave every year, while this situation was never observed before.

Within the 2000-2009 decade, the sole year of 2003 totals $59 \%$ of the heat wave days*departments and $85 \%$ of the cumulated severity over the decade. In total, $5114^{\circ} \mathrm{C}$ cumulated over thresholds were recorded in 2003, representing $45 \%$ of the total number of degrees above thresholds cumulated between 1970 and 2019. An acceleration in the exposure to extreme heat is observed since 2015 (Fig. 2).

Between 2003 and 2019, 833 departmental heat waves were observed, encompassing all the regions of France; 434 (65\%) of them occurred between 2015 and 2019 (Supplementary material Fig. S2). Details (intensity, severity, duration) of departmental heat waves observed since 2003 are presented in Supplementary material Fig. S3. With higher intensities, and wider geographical spread of heat waves since 2015, we observed a sharp increase in the annual populationweighted severity since 2015 , while still not reaching the levels observed in 2003 (Fig. 3). Figure 4 illustrates how this translates into an increase in the number of heat warnings, with the activation of the red level for the first time in 2019.

Changes in the geographical spread directly challenge the system, resulting in an increase pressure of warnings in some departments where heat waves are now observed every year (e.g. in the Paris and Lyon regions), and the occurrence of events without historical equivalent in some departments (e.g. in the North of France) (Supplementary material Fig. S2).

Temporal changes are also observed, with events observed early in June for the first time in 2015, then 2017 and 2019, and late in September for the first time in 2016. The operating period was therefore extended from the $1^{\text {st }}$ June to the $15^{\text {th }}$ September in 2018.

Annual feedbacks have confirmed that warnings based on the meteorological forecasts allowed for the early identification of dangerous heat waves (through a comparison of forecasted and observed data, and an analysis of the timelines of warnings). Evaluation shows a tendency to issue more warnings than the actual exceedance of the thresholds, while it seldom happened that observed thresholds exceedances were not anticipated by a warning. However, since 2015, the warning system was challenged by several situations, e.g., (1) record-breaking diurnal temperatures associated with moderate night temperatures, (2) record-breaking night temperatures associated with moderate exposure during the day, (3) extreme day to day temperature variations, and (4) high geographical variations. For instance, in 2019, the maximum temperature exceeded $40^{\circ} \mathrm{C}$ for almost one week in several departments, and reached $46^{\circ} \mathrm{C}$ in the South East of France. Criteria to manage such situation (extreme temperature, highly localized, and for a short period of time) had to be developed in a few hours, and experimented during the summer, before being able to confirm them based on an ad hoc retrospective study (Le Tertre et al. 2020). The 2019 heat wave remodelled the entire philosophy of the highest level of the warning system. This level had initially been designed for long-lasting and widespread heat waves that were already affecting health and economic sectors. Temperatures between $40^{\circ} \mathrm{C}$ and $46^{\circ} \mathrm{C}$ for a very short period of time were not anticipated, and it became clear that the current system was not protective under such conditions. Since 2019, the red level now targets situations of extreme risk for the majority of the population, independently of their duration, or of the occurrence of multi-sector impacts.

Table 2 Main historical trends observed in France

\begin{tabular}{|c|c|c|c|c|c|c|c|}
\hline & $\begin{array}{l}\text { Number of departments } \\
\text { experiencing at least one } \\
\text { heat wave during the } \\
\text { period }\end{array}$ & $\begin{array}{l}\text { Number of heat } \\
\text { wave days * } \\
\text { department during } \\
\text { the period }\end{array}$ & $\begin{array}{l}\text { Number of } \\
\text { years } \\
\text { without any } \\
\text { heat wave }\end{array}$ & $\begin{array}{l}\text { Number of } \\
\text { departments with } \\
\text { at least one heat } \\
\text { wave per year }\end{array}$ & $\begin{array}{l}\text { Cumulated } \\
\text { severity } \\
\text { over the } \\
\text { decade }\left({ }^{\circ} \mathrm{C}\right)\end{array}$ & $\begin{array}{l}\text { Cumulated exposure } \\
\text { (population } *{ }^{\circ} \mathrm{C} \text { above } \\
\text { thresholdsmillions } \\
\text { person }{ }^{\circ} \mathrm{C} \text { ) }\end{array}$ & $\begin{array}{l}\text { Excess } \\
\text { mortality during } \\
\text { heat waves } \\
\text { (mean estimate) }\end{array}$ \\
\hline $1970-1979$ & 50 & 515 & 5 & 0 & 1273 & 943 & 6547 \\
\hline 1980-1989 & 85 & 666 & 5 & 0 & 758 & 356 & 4113 \\
\hline 1990-1999 & 76 & 681 & 2 & 0 & 717 & 511 & 3111 \\
\hline $2000-2009$ & 96 & 2.130 & 1 & 0 & 5991 & 3794 & 17,190 \\
\hline 2003 & 96 & 1.267 & - & - & 5114 & 3154 & 15,257 \\
\hline $2010-2019$ & 95 & 2.859 & 1 & 11 & 2676 & 2027 & 6407 \\
\hline 2015-2019 & 95 & 2.252 & 0 & 11 & 2103 & 1717 & 5700 \\
\hline
\end{tabular}


Fig. 2 Cumulated degree above thresholds, and cumulated excess mortality during heat waves between 1970 and 2019
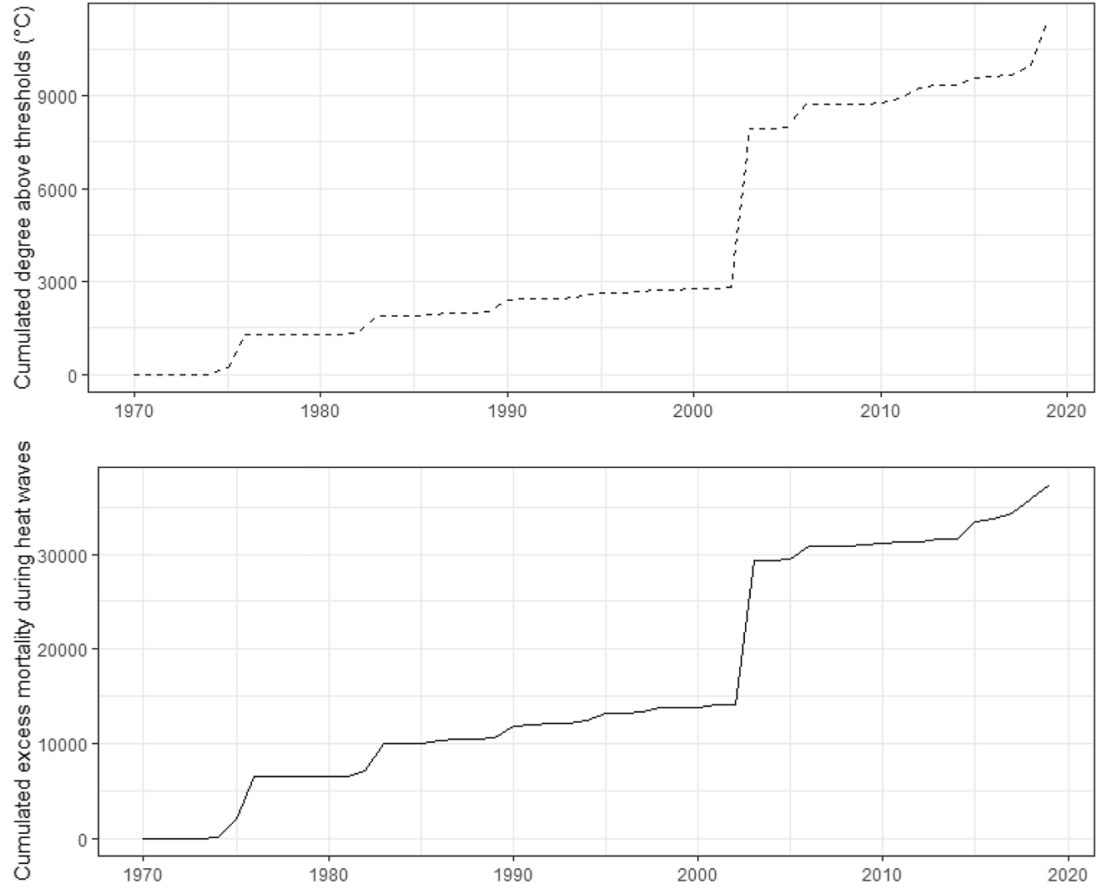

Feedbacks also revealed a misunderstanding of the thresholds by some stakeholders, who considered that there was no risk nor impact below thresholds, and therefore neglected the yellow warnings. A study based on indepth interviews with key stakeholders of six cities concluded that they considered that the heat-related risks were "under control", based on the application of "common sense" and "routine" management. This may contribute to a form of risk trivialization that may prove dangerous in the long term. A new concern with the apparition of red warnings is that the risk perception of orange warnings will now decrease among the general population and among stakeholders.

\section{An increase in the mortality and morbidity impacts despite prevention}

More than 37,000 excess deaths were observed during heat waves since 1970 (Fig. 2). The deadliest heat waves (in absolute number of deaths) were observed in $2003(+15,257$ deaths), $1976(+4540), 1983(+2900), 1975(+1975), 2015$ $(+1727), 2018(+1641)$ and $2019(+1462)$.
Fig. 3 Population weighted severity of the heat waves observed per year since 2003

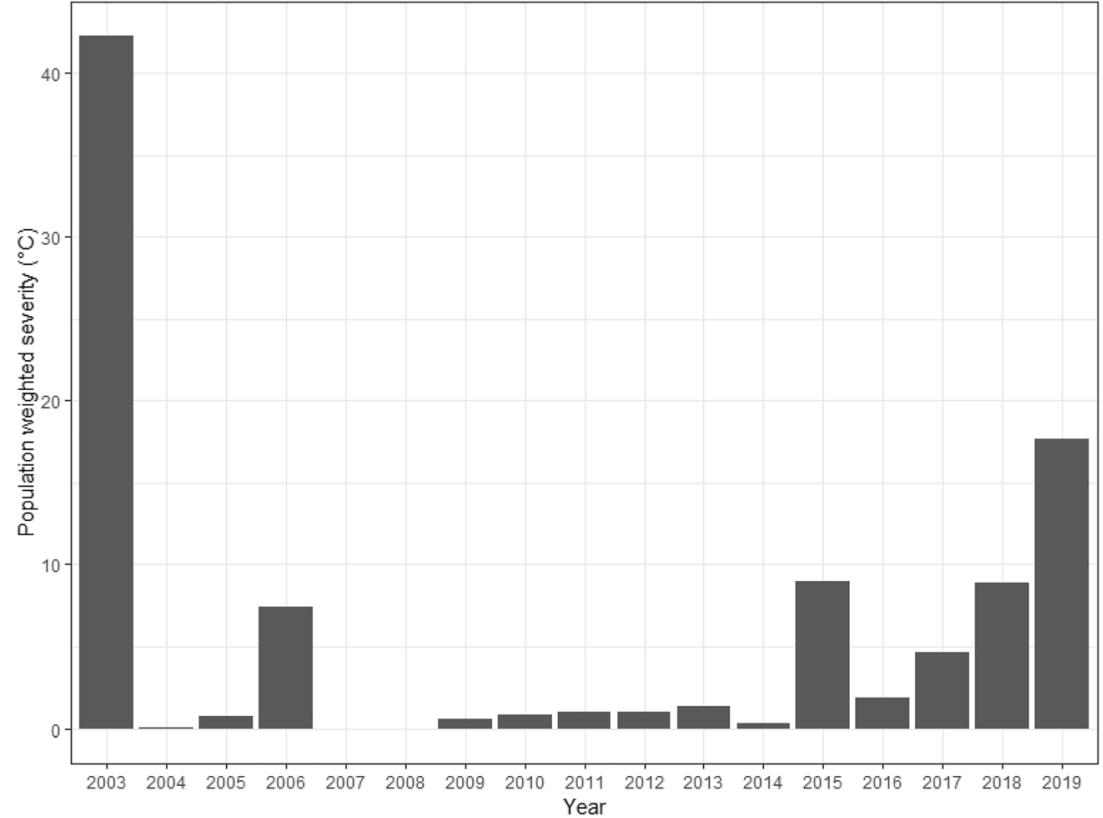


Fig. 4 Number of warnings per year since 2004 (each warning represents a department and a day)

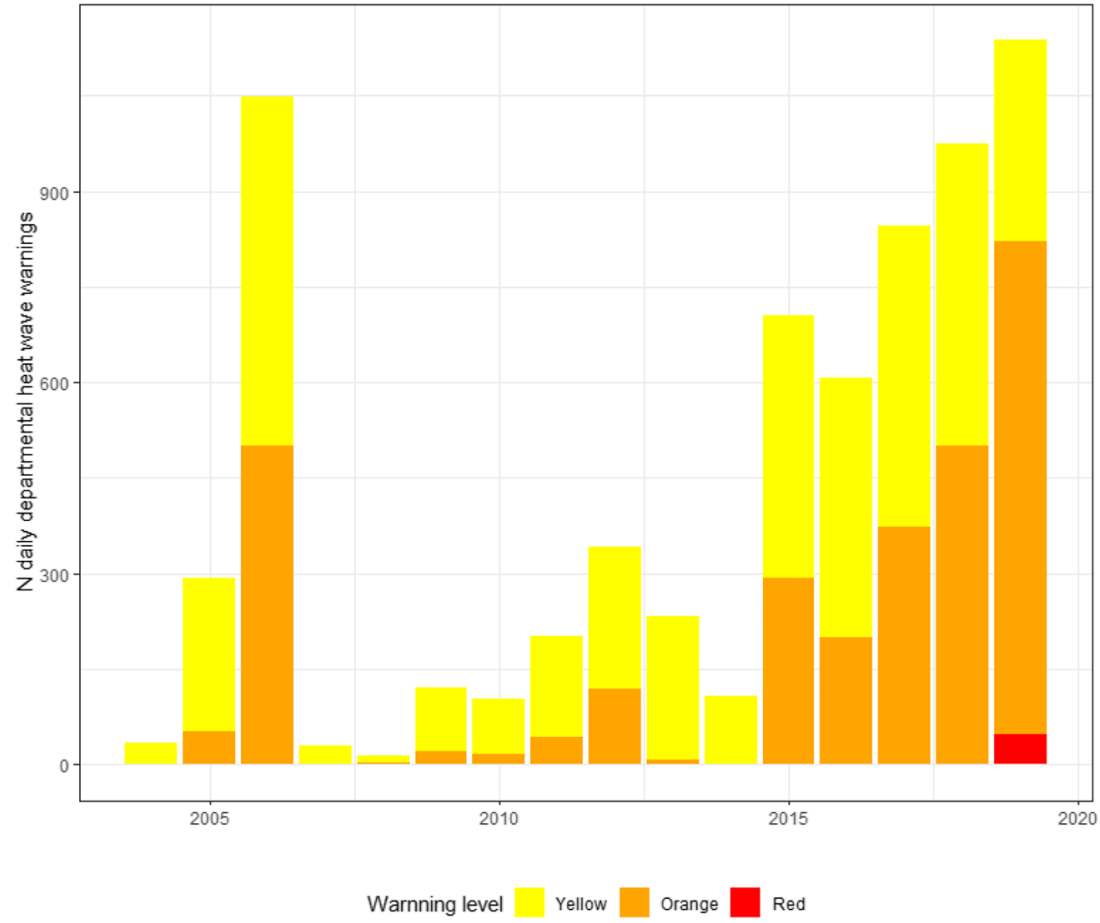

Between 2004 and 2019, 8000 excess deaths were observed during heat waves. In the following, we only detailed the mortality for the 2015-2019 period (Table 3 and Supplementary material Table 1), as it represents $71 \%$ of the total excess mortality observed since 2004 (5700 excess deaths between 2015 and 2019). Table 3 summarized the relative excess mortality during heat waves per age groups. Estimates for children under 15, and adults aged 15-44 are difficult to interpret given the very low mortality rates. However, we note an increase in the mortality impacts in the 15-44 age groups in the recent years. People aged 75 years old and over contribute the most to the excess mortality in absolute number, but not always in relative excess. The 65-74 years age group was severely impacted, with excesses higher than $25 \%$ on 2016 and 2018. In total, 419 people aged 45-64 years old have died during heat waves between 2015 and 2019, 1324 aged 65-74 years old, and 3855 aged 75 years old and over. The repartition of the mortality impact per age group varies between years.

Between 16,000 and 22,000 emergency room (ER) visits were registered for hyperthermia, dehydration and hyponatremia each summer since 2015. Almost half of these visits concerned dehydration and a third hyponatremia and people over 75 years old. Only a fraction of those visits is observed during heat waves (Table 2), with the exception of ER visits for hyperthermia in 2019 for all age-groups. Figure 5 illustrates the daily trends in ER visits per causes for 2019 (years 2015-2018 are described in Supplementary Material Figs. 4 to 7). Periods of heat waves always coincide with the peaks in activity for the selected causes.
In 2017, studies on the completeness of the emergency data showed that only trends in proportions of activity could be analyzed in near-real time. This led to the decision to reduce the information communicated to stakeholders. While Santé publique France analyses the data daily, it only communicates weekly on the observed impacts, except if the analyses point out that something highly unusual is occurring (i.e. numbers or rates higher than what is expected for the period, specific age groups, new symptoms...). The need for such early communication is qualitatively appreciated by the local epidemiologists.

Health surveillance data were never used to decide for a warning, as at risk situations have always been anticipated by the meteorological warning system.

\section{Prevention measures}

In 2019, approximately 734,000 documents were distributed ( $87 \%$ leaflets, $13 \%$ posters), $75 \%$ of those before the first heat waves of the summer. Television and radio spots were largely broadcasted on the media. Similar order of magnitudes of number of documents and broadcasts were disseminated in the preceding years.

A study was carried out in October 2015 on a sample of 2504 individuals aged 18 and over, on health attitudes or behaviors during heat waves (Laaidi et al. 2019a). Most of the respondent (88\%) did not feel at risk, even among the individuals aged 65 and over. $4 \%$ of the people aged 65 and over considered they were at high risk during a heat wave compared to $2 \%$ among the $18-65$ years old, 
Table 3 Relative excess mortality $(\%)$ and $\%$ of emergency room visits for heat-related causes occurring during heat waves

\begin{tabular}{|c|c|c|c|c|c|}
\hline & Year & Excess mortality (\%) & $\begin{array}{l}\text { Hyperthermia } \\
\text { (\% of visits occurring } \\
\text { during heat waves) }\end{array}$ & $\begin{array}{l}\text { Dehydration } \\
\text { (\% of visits occurring } \\
\text { during heat waves }\end{array}$ & $\begin{array}{l}\text { Hyponatremia } \\
\text { (\% of visits occurring } \\
\text { during heat waves }\end{array}$ \\
\hline \multirow[t]{5}{*}{ Under 15} & 2015 & $16.4 \%$ & $27 \%$ & $14 \%$ & $0 \%$ \\
\hline & 2016 & $-21.0 \%$ & $5 \%$ & $2 \%$ & $3 \%$ \\
\hline & 2017 & $-19.2 \%$ & $22 \%$ & $9 \%$ & $5 \%$ \\
\hline & 2018 & $12.1 \%$ & $23 \%$ & $13 \%$ & $12 \%$ \\
\hline & 2019 & $2 \%$ & $37 \%$ & $17 \%$ & $16 \%$ \\
\hline \multirow[t]{5}{*}{ 15-44 years } & 2015 & $-4.8 \%$ & $25 \%$ & $17 \%$ & $13 \%$ \\
\hline & 2016 & $-4.1 \%$ & $4 \%$ & $2 \%$ & $3 \%$ \\
\hline & 2017 & $7.4 \%$ & $21 \%$ & $11 \%$ & $12 \%$ \\
\hline & 2018 & $12.5 \%$ & $22 \%$ & $15 \%$ & $12 \%$ \\
\hline & 2019 & $12.5 \%$ & $44 \%$ & $22 \%$ & $15 \%$ \\
\hline \multirow[t]{5}{*}{ 45-64 years } & 2015 & $9.8 \%$ & $25 \%$ & $13 \%$ & $11 \%$ \\
\hline & 2016 & $6.4 \%$ & $6 \%$ & $2 \%$ & $3 \%$ \\
\hline & 2017 & $2.2 \%$ & $23 \%$ & $10 \%$ & $6 \%$ \\
\hline & 2018 & $8.0 \%$ & $24 \%$ & $15 \%$ & $11 \%$ \\
\hline & 2019 & $3.6 \%$ & $46 \%$ & $20 \%$ & $16 \%$ \\
\hline \multirow[t]{5}{*}{$65-74$ years } & 2015 & $13.7 \%$ & $29 \%$ & $16 \%$ & $12 \%$ \\
\hline & 2016 & $27.2 \%$ & $7 \%$ & $2 \%$ & $3 \%$ \\
\hline & 2017 & $9.6 \%$ & $21 \%$ & $10 \%$ & $9 \%$ \\
\hline & 2018 & $25.4 \%$ & $22 \%$ & $16 \%$ & $12 \%$ \\
\hline & 2019 & $13.0 \%$ & $47 \%$ & $23 \%$ & $16 \%$ \\
\hline \multirow[t]{5}{*}{ Over 75} & 2015 & $22.5 \%$ & $33 \%$ & $17 \%$ & $14 \%$ \\
\hline & 2016 & $12.7 \%$ & $11 \%$ & $3 \%$ & $3 \%$ \\
\hline & 2017 & $6.2 \%$ & $38 \%$ & $12 \%$ & $10 \%$ \\
\hline & 2018 & $14.2 \%$ & $28 \%$ & $18 \%$ & $14 \%$ \\
\hline & 2019 & $9.4 \%$ & $50 \%$ & $23 \%$ & $20 \%$ \\
\hline
\end{tabular}

whereas 40\% said having suffered during the 2015 heat wave. Dehydration was a well-known risk $(78 \%)$ but the other health-related illnesses were less known and their hazardousness was underestimated. $32 \%$ of the participants were able to define heat stroke and only $38 \%$ considered it dangerous. The lack of knowledge concerning prevention measures and warning signs for heat-related illnesses did not increase since 2006 (Léon et al. 2007).

93\% of the participants knew at least one of the 7 tips given on the leaflet to cope with heat wave. If $92 \%$ of the interviewed people knew that it is important to keep hydrated and drink water, $17 \%$ of the elderly did not follow that advice. $88 \%$ of parents avoid outdoors activities during the hottest hours or keep children in the shade. $57 \%$ of the participants visited their close relatives during the heat waves and $10 \%$ welcomed them in their home. But if solidarity seems to play an important role, asking for professional help is far less common: $11 \%$ of the elderly benefited from a homecare, and only $4 \%$ of them registered to the city registers for vulnerable people.
Although we do not have a comprehensive database of actions taken locally, examples of actions taken in 2019 included the cancelling of a national exam for junior school students (due to the impossibility to guarantee safe indoor temperatures) and of several sports manifestations, advises not to take public transportation (to avoid over-exposure in trains without air conditioning), changes in work organization....

\section{Discussion}

\section{Meteorological trends and the adaptation of warning system}

Recent trends in heat waves observed in France are consistent with the worldwide picture of a fast-warming world (IPCC 2018). The historical analysis of heat waves, as defined by the heat wave warning system, indicates rapid changes, with a number of events that has increased brutally first in the 
Fig. 5 Percentage of the French population exposed to heat wave (departmental observed temperature above the warning thresholds) and daily number of total number of emergency room visits for dehydration, hypothermia and hyponatremia during summer 2019 (all ages)
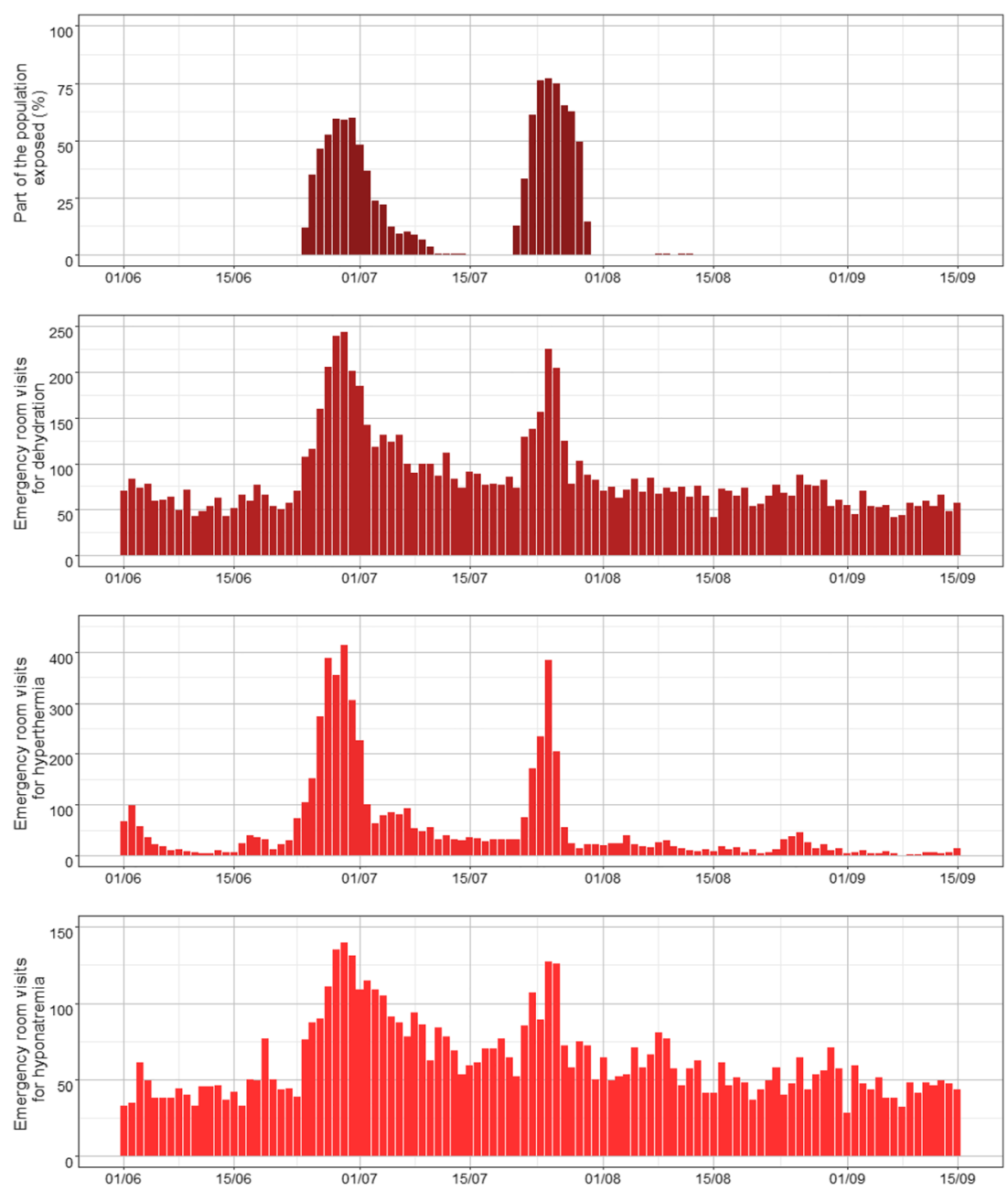

2000s and then after 2015. While still incomparable to 2003, heat waves observed since 2015 were highly disruptive. In some departments, heat warnings are now extremely frequent, and mobilize large resources. In others, record-breaking temperatures are observed, exposing a population who has no historical experience of heat. High inter-day variations can now be observed, or night temperature exceeding $20^{\circ} \mathrm{C}$ or more during several hours.

The warning system had to adapt rapidly to unusual situations, taking immediate decision, like the evolution of the red level in 2019. Those decisions are based on expertise, and need to be confirmed or infirmed afterwards by epidemiological studies. Yet, such studies are usually based on historical data, and when their results are available, new situations are already experienced. An additional difficulty is that multiple factors may intervene in the health impacts of a given heat wave: its intensity, duration, periods of the summer, associated contextual risk factors, access to health care equipment, social background, equipment of the population in air conditioning, actions developed at the city level, etc. Given the multiplicity of stakeholders who are now interested in heat wave prevention, and the diversity of their actions, it is extremely difficult to disentangle the warning, the prevention, and the observed impacts. For instance, is the 2019 impact explained by the localization of the heat wave, its short duration, or by the efficiency of the red warnings? The capacity of current epidemiological models to answer these questions is limited by the absence of comparable temperatures in the past, and the lack of data on what is actually implemented at the local level.

All this directly questions the geographical scale at which a heat warning system and prevention plan must be implemented. While a national response is relevant to ensure equity, and makes sense when all departments had a limited experience of heat waves, how could we take into account the diversity of the local situations? Is it appropriate to have the same objectives of the warning system in departments that are now experiencing systematically multiple heat waves per summer, and in departments where they still are rare events? Should we set the same objective in a department experiencing several heat waves each year, and in a department experiencing its first heat wave?

Finally, risk perception remains a key issue, which contributes to limit the willingness of stakeholders to take strong measures. The risk of eroding risk perception as the number of warnings increase is real. 
In the recent years, there has been a strong increase in research interest on heat warning systems, with several new approaches proposed to compute thresholds, some purely based on epidemiology and biostatistics (McElroy et al. 2020), and others describing participatory approaches with stakeholders (Henderson et al. 2020). A convergence between those approaches, taking into account the features of the most recent heat waves is highly needed to design efficient, flexible and acceptable warning systems.

In addition, efforts to develop consensual heat wave definition and metrics, comparable through time and space, easily computed and understandable by a wide range of stakeholders would be helpful to increase risk perception, and support decision-making.

\section{Limited possibilities to evaluate the prevention plans based on available health data}

Measuring the mortality and morbidity impacts of heat waves remains challenging despite improvement in surveillance and modelling. A better knowledge of those impacts in terms of risk determinants and characteristics of people impacted is needed to improve prevention. However, in France, access to key data such as the causes of deaths takes a minimum of 4 years, a delay that becomes deleterious when considering the rapidity of the environmental trends we are facing.

An evaluation based on morbidity impacts is limited, since such data was not available before 2004, and extensive, stable dataset are only available since 2015 . Yet, we did not observe a decrease in morbidity in the recent years. As for mortality, we have no clear indication of a change in the temperaturemorbidity response before and after 2004 (Pascal et al. 2018). A retrospective analysis of heat waves between 1974 and 2013 found that a one unit increase in intensity was associated to a relative risk of deaths of $1.17[1.16 ; 1.18]$ before 2003 and a relative risk of 1.17 [1.10; 1.21] after 2003 (Pascal et al. 2019). It is worth noting that there is no correlation between the trends observed in mortality and morbidity, which suggests that these indicators represent distinct population and patterns of exposure.

Finally, detailed information on the interventions taken at the local level is missing, limiting our capacity to evaluate their efficiency.

\section{The need to shift from prevention to adaptation}

Feedbacks concluded that warnings were timely issued, and studies found that a majority of the population knew and followed some recommendations. Yet, individual risk perception remains low, and recommendations such as reducing physical activity are still poorly respected (Laaidi et al. 2019a). Stakeholders also reported organizational difficulties to maintain and evaluate heat management strategies, as well as a poor knowledge of the actual health impact, and a tendency to implement actions based on their own heat perception rather than based on the heat warnings (Laaidi et al. 2019b). Due to the geographic spread and the ubiquity of exposure, most of the time the fatalities are not directly nor immediately observable, which may contribute to a feeling of safety. Similarly, mortality impacts are either compared to 2003 impacts, even when the intensity and duration of the heat waves are totally different, or not known at all, leading to a feeling of efficiency.

Today, in France, heat waves prevention is structured around communication, warnings, and on a lesser level organizational changes. Its efficiency will depend on risk perception, and on adoption of appropriate behaviors. Yet, risk perception remains low. Furthermore, in 2019, several actions that were taken resulted in restricted activities or canceling of events, because it was no more possible to ensure safe indoor conditions, in schools or public transportation for instance. This prevention came at a high social and economic cost. The efficiency and the acceptability of similar measures in case of a longer heat wave is questionable, and should be organized in advance instead of during the crisis, in association with the stakeholders in the field. This underlines that prevention must go beyond individual measures, and promote multi-sectoral adaptation to heat.

So far, adaptation to heat waves remains mostly reactive, learning on new events to evolve procedures. As environmental exposure to extreme heat speeds up, it becomes more and more difficult to keep on track and maintain an efficient warning and prevention plan. Time has become a major obstacle to adaptation. Even worst heat waves are expected in the next decades, and the trends until 2040 are unlikely to be modified by trajectories of greenhouse gases emissions (IPCC 2018). Climate change is also increasing the risk of cascading crises, 2019 and 2020 already provide examples of situations were heat waves have prevention needs to take into account other major health risks. In Australia, extreme heat was associated with forest fires, and acute air pollution episodes (Hope 2020). In spring 2020, work is going-on to anticipate, and control as much as possible, the expected negative impacts on a heat wave occurring in an era largely impacted by the COVID-19 pandemic (with implications for the safety of health workers, acceptability of the sheltering measuring, reorganization of the surveillance strategy...).

A specific attention should be given to increase the number of resources allocated to the evaluation and the management heat surveillance, prevention and adaptation, considering the needs to catch with the rapid rhythm of heat wave changing characteristics.

Since there is no evidence that such adaptation would still be possible under high-range warming scenarios, mitigation to avoid unmanageable heat waves after 2040 is an asset to protect future generations (IPCC 2018). 
Supplementary Information The online version contains supplementary material available at https://doi.org/10.1007/s00484-021-02123-y.

Author's contribution MP; writing — original draft preparation, RL; data analysis, writing, review, AT; writing, review, IB; writing, review, KL; writing, review, SC; writing, review, ALT; writing, review, SD; supervision.

\section{References}

Anderson BG, Bell ML (2009) Weather-related mortality: how heat, cold, and heat waves affect mortality in the United States. Epidemiology. 20(2):205-213

Antics A, Pascal M, Laaidi K, Wagner V, Corso M, Declercq C, Beaudeau P (2013) A simple indicator to rapidly assess the shortterm impact of heat waves on mortality within the French heat warning system. Int J Biometeorol 57(1):75-81

Atiki N, Pascal M, Wagner V (2018) Influence de la chaleur sur quelques causes de recours aux soins d'urgences en France métropolitaine durant les étés 2015-2017. Bulletin épidémiologique hebdomadaire $1: 6$

Basarin B, Lukić T, Matzarakis A (2020) Review of biometeorology of heatwaves and warm extremes in Europe. Atmosphere 11(12):1-21

Basu R (2009) High ambient temperature and mortality: a review of epidemiologic studies from 2001 to 2008. Environ Health 8(1)

Benmarhnia T, Deguen S, Kaufman JS, Smargiassi A (2015) Vulnerability to heat-related mortality: a systematic review, metaanalysis, and meta-regression analysis. Epidemiology 26(6):781793

Bittner MI, Matthies EF, Dalbokova D, Menne B (2014) Are European countries prepared for the next big heat-wave? Eur J Pub Health 24(4):615-619

Campbell S, Remenyi TA, White CJ, Johnston FH (2018) Heatwave and health impact research: a global review. Health Place 53:210-218

Casanueva A, Burgstall A, Kotlarski S, Messeri A, Morabito M, Flouris $\mathrm{AD}$ et al (2019) Overview of existing heat-health warning systems in Europe. Int J Environ Res Public Health 16(15)

Caserio Schonemann C, Bousquet V, Fouillet A, Henry V (2014) Le système de surveillance syndromique SurSaUD®. Bull Epidemiol Hebd (3-4):38-44

Chapman SC, Watkins NW, Stainforth DA (2019) Warming trends in summer heat waves. Geophys Res Lett

David F (2015) Prévention des risques liés à la canicule et aux fortes chaleurs. La Santé en actions 432:33-34

Diffenbaugh NS, Singh D, Mankin JS, Horton DE, Swain DL, Touma D, Charland A, Liu Y, Haugen M, Tsiang M, Rajaratnam B (2017) Quantifying the influence of global warming on unprecedented extreme climate events. Proc Natl Acad Sci U S A 114(19):4881-4886

Gasparrini A, Guo Y, Hashizume M, Lavigne E, Zanobetti A, Schwartz J, Tobias A, Tong S, Rocklöv J, Forsberg B, Leone M, de Sario M, Bell ML, Guo YLL, Wu CF, Kan H, Yi SM, de Sousa Zanotti Stagliorio Coelho M, Saldiva PHN, Honda Y, Kim H, Armstrong B (2015) Mortality risk attributable to high and low ambient temperature: a multicountry observational study. Lancet 386(9991): 369-375

Green H, Bailey J, Schwarz L, Vanos J, Ebi K, Benmarhnia T (2019) Impact of heat on mortality and morbidity in low and middle income countries: a review of the epidemiological evidence and considerations for future research. Environ Res 171:80-91

Hajat S, Kosatky T (2010) Heat-related mortality: a review and exploration of heterogeneity. J Epidemiol Community Health 64(9): $753-760$
Hajat S, Sheridan SC, Allen MJ, Pascal M, Laaidi K, Yagouti A, Bickis U, Tobias A, Bourque D, Armstrong BG, Kosatsky T (2010) Heathealth warning systems: a comparison of the predictive capacity of different approaches to identifying dangerously hot days. Am J Public Health 100(6):1137-1144

Hanna EG, Tait PW (2015) Limitations to thermoregulation and acclimatization challenge human adaptation to global warming. Int J Environ Res Public Health 12(7):8034-8074

Henderson D, Aubin L, Behan K, Chen H, Doyle H, Gower S, MacDonald M, Mee C, Richardson GRA, Rochon G, Shnabel M, Storfer J, Yagouti A, Yusa A (2020) Developing a harmonized heat warning and information system for Ontario: a case study in collaboration. Can J Public Health 111(3):426-432

Hope M (2020) Australia burning. Lancet Planet Health 4(1):e12-ee3

IPCC (2018) Special Report on Global Warming of $1.5^{\circ} \mathrm{C}$ - Technical summary. Geneva. 1:25 p. Available from: https://www.ipcc.ch/ sr15/

Ito K, Lane K, Olson C (2018) Equitable access to air conditioning: a city health department's perspective on preventing heat-related deaths. Epidemiology. 29(6):749-752

Josseran L, Fouillet A, Caillere N, Brun Ney D, Ilef D, Brucker G et al (2010) Assessment of a syndromic surveillance system based on morbidity data results from the Oscour network during a heat wave. PLoS One 5(8)

Laaidi K, Perrey C, Léon C, Mazzoni M, Beaudeau P (2019a) Connaissances, attitudes et comportements des français face à la canicule. la Santé en actions (448):2

Laaidi K, Mazzoni M, Perrey C, Beaudeau P, Pascal M (2019b) Canicule et personnes vulnérables : enquête sur les registres municipaux. $\mathrm{La}$ Santé en Actions 448:2

Le Tertre A, Lefranc A, Eilstein D, Declercq C, Medina S, Blanchard M et al (2006) Impact of the 2003 heatwave on all-cause mortality in 9 French cities. Epidemiology 17(1):75-79

Le Tertre A, Pascal M, Lagarrigue R, Wagner V, Laaidi K (2020) Définition de critères d'aide à la décision pour la vigilance rouge canicule (Definition of decision-support criteria for triggering the red alert level for heatwaves). Saint-Maurice: Santé publique France. 19 p. p. Available from: https://www.santepubliquefrance. $\mathrm{fr} /$ determinants-de-sante/climat/fortes-chaleurs-canicule/ documents/enquetes-etudes/definition-de-criteres-d-aide-a-ladecision-pour-la-vigilance-rouge-canicule

Léon C, Girard D, Ardwison P, Guilbert P (2007) Comportements préventifs des Français et impact des campagnes de prévention durant la canicule 2006. Evolutions [Internet]. (7):1-6

Lowe D, Ebi KL, Forsberg B (2011) Heatwave early warning systems and adaptation advice to reduce human health consequences of heatwaves. Int J Environ Res Public Health 8(12):4623-4648

McElroy S, Schwarz L, Green H, Corcos I, Guirguis K, Gershunov A, Benmarhnia T (2020) Defining heat waves and extreme heat events using sub-regional meteorological data to maximize benefits of early warning systems to population health. Sci Total Environ 721: 137678

McGregor G, Bessemoulin P, Ebi K, Menne B (2015) Heatwaves and Health: Guidance on Warning-System Development. Dans: organization WmoWh, rédacteur. Geneva, Switzerland, p 96

Pascal M, Laaidi K, Ledrans M, Baffert E, Caserio-Schonemann C, Le Tertre A et al (2006) France's heat health watch warning system. Int J Biometeorol 50(3):144-153

Pascal M, Laaidi K, Wagner V, Ung AB, Smaili S, Fouillet A et al (2012) How to use near real-time health indicators to support decisionmaking during a heat wave: the example of the French heat wave warning system. PLoS Curr 4:e4f83ebf72317d

Pascal M, Wagner V, Le Tertre A, Laaidi K, Honore C, Benichou F et al (2013) Definition of temperature thresholds: the example of the French heat wave warning system. Int J Biometeorol 57(1):21-29 
Pascal M, Wagner V, Corso M, Laaidi K, Ung A, Beaudeau P (2018) Heat and cold related-mortality in 18 French cities. Environ Int 121: $189-198$

Pascal M, Wagner V, Corso M, Laaidi K (2019) A. LT. Évolution de l'exposition aux canicules et de la mortalité associée en France métropolitaine entre 1970 et 2013. Santé publique France, SaintMaurice, 69 p Available from: www.santepubliquefrance.fr

Perkins SE (2015) A review on the scientific understanding of heatwaves - their measurement, driving mechanisms, and changes at the global scale. Atmos Res 164-165:242-267

Piticar A (2018) Changes in heat waves in Chile. Glob Planet Chang 169: 234-246

Robine J-M, Cheung SLK, Le Roy S, Van Oyen H, Griffiths C, Michel J$P$ et al (2008) Death toll exceeded 70,000 in Europe during the summer of 2003. C R Biol 331(2):171-178

Russo S, Dosio A, Graversen RG, Sillmann J, Carrao H, Dunbar MB, Singleton A, Montagna P, Barbola P, Vogt JV (2014) Magnitude of extreme heat waves in present climate and their projection in a warming world. J Geophys Res-Atmos 119(22):12500-12512

Russo S, Sillmann J, Fischer EM (2015) Top ten European heatwaves since 1950 and their occurrence in the coming decades. Environ Res Lett 10(12)

Santé publique France (2020) Nombre de décès en excès pendant les périodes de canicule 1974-2020 [Excess mortality during heat waves in France 1974-2020] [Internet]. [updated; cited]. Available from: https://geodes.santepubliquefrance.fr/

Sera F, Hashizume M, Honda Y, Lavigne E, Schwartz J, Zanobetti A, Tobias A, Iñiguez C, Vicedo-Cabrera AM, Blangiardo M, Armstrong B, Gasparrini A (2020) Air conditioning and heatrelated mortality: a multi-country longitudinal study. Epidemiology. 31:779-787

Shaposhnikov D, Revich B, Bellander T, Bedada GB, Bottai M, Kharkova T, Kvasha E, Lezina E, Lind T, Semutnikova E,
Pershagen G (2014) Mortality related to air pollution with the Moscow heat wave and wildfire of 2010. Epidemiology. 25(3): 359-364

Sheridan SC, Lee CC (2018) Temporal trends in absolute and relative extreme temperature events across North America. J Geophys Res Atmos 123(21):11,889-111,98

Solomon SD, Quin D, Manning M, Chen Z, Marquis M, Averyt KB et al (2007) Contribution of Working Group I to the Fourth Assessment Report of the Intergovernmental Panel on Climate Change, 2007. Cambridge, United Kingdom and New York, NY, USA, 1-996 p

Soubeyroux JMOG, Schneider M, Cabanes O, Kounkou R (2016) Les vagues de chaleur en France: analyse de l'été 2015 et évolutions attendues en climat futur. La Météorologie (94):45-51

Tong S, FitzGerald G, Wang XY, Aitken P, Tippett V, Chen D, Wang X, Guo Y (2015) Exploration of the health risk-based definition for heatwave: a multi-city study. Environ Res 142:696-702

vanOldenborgh G, Philip S, Kew S, Vautard R, Boucher O, Otto F et al (2019) Human contribution to the record-breaking June 2019 heat wave in France. 1:32 p. Available from: https://www. worldweatherattribution.org/wp-content/uploads/WWA-Science France_heat_June_2019.pdf

Vautard R, Boucher O, vanOldenborgh G, Otto F, Haustein K, Vogel M et al (2019) Human contribution to the record-breaking July 2019 heat wave in Western Europe. 1:32 p. Available from: https://www. worldweatherattribution.org/wp-content/uploads/WWA-Science France heat_June 2019.pdf

Xu Z, FitzGerald G, Guo Y, Jalaludin B, Tong S (2016) Impact of heatwave on mortality under different heatwave definitions: a systematic review and meta-analysis. Environ Int 89-90:193-203

Publisher's Note Springer Nature remains neutral with regard to jurisdictional claims in published maps and institutional affiliations. 